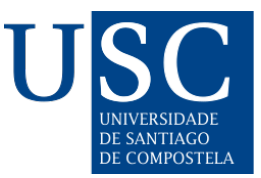

\title{
JUSTICIA TRANSICIONAL PARA LA SUPERACIÓN DEL DILEMA COLOMBIANO
}

TRANSITIONAL JUSTICE TO OVERCOME THE COLOMBIAN DILEMMA

Diana Patricia Arias Henao iD

Universidad Militar Nueva Granada, Colombia

Recibido: 08/10/2020; Aceptado: 12/01/2021

\section{Resumen}

El presente artículo de reflexión tiene como objetivo analizar la justicia restaurativa desde la relación individuo-sociedad y dentro del proceso de paz específico con las Fuerzas Armadas Revolucionarias de Colombia, Farc-Ep. Recorre sus antecedentes históricos hasta la consecución de una Justicia Especial para la Paz - JEP, como modelo de justicia transicional. Con una metodología descriptiva que utiliza instrumentos cualitativos y comparativos de medición con otros procesos transicionales de justicia como el caso de Irlanda del Norte y Sudáfrica, se presentan resultados en materia de escenarios de construcción de paz. Se propone a la teoría política contemporánea como un marco de comprensión conceptual de la urgencia de un modelo de justicia que esté a la altura de las circunstancias y los tiempos colombianos.

Palabras clave: Justicia transicional; Conflicto armado; Colombia; Procesos de paz.

\section{Abstract}

The purpose of this reflection article is to analyze restorative justice from the individual-society relationship and within the specific peace process with the Revolutionary Armed Forces of Colombia, FarcEp. It traces its historical antecedents until the achievement of a Special Justice for Peace - JEP, as a model of transitional justice. With a descriptive methodology that uses qualitative and comparative instruments of measurement with other transitional justice processes such as the case of Northern Ireland and South Africa, results are presented in terms of peacebuilding scenarios. Contemporary political theory is proposed as a framework for conceptual understanding of the urgency of a justice model that is up to the Colombian circumstances and times.

Keywords: Transitional justice; Armed conflict; Colombia; Peace process.

\section{INTRODUCCIÓN}

Uno de los mayores retos que tiene el sistema colombiano en materia de justicia es el de repensar la justicia y ofrecer nuevos canales de solución a los conflictos que incluyan modelos de justicia, 
reparación y disminución del crimen. Esta es una tarea titánica que no será resuelta rápidamente. Quizá la tarea más urgente sea la de dejar de comprender el crimen como parte de una acción individual, movida por las intenciones de un sujeto y pasar a comprender el crimen dentro de una trama estructural que va convirtiendo a los sujetos en parte de una maquinaria criminal, si bien esto no se puede aseverar de todos los crímenes, sí se puede afirmar de aquellos que tienen unas profundas raíces estructurales, que cimientan el conflicto armado interno.

De igual forma, las llamadas narco-comunidades (Arias, 2014) han operado de ese modo durante años, reclutando sujetos vulnerables y convirtiéndolos en sus principales aliados, reproduciendo toda una serie de conflictos estructurales en el marco de acciones de las que no solo son responsables los sujetos que actúan. Sino también la debilidad estatal.

Si bien las estructuras criminales son el principal elemento dentro de la formación de sujetos peligrosos, esto no exonera de responsabilidad al sujeto que comete el crimen, por lo que el tratamiento de la justicia no es solo una cuestión en el orden del castigo, sino que tiene que ver también con un re-ensamblaje ético. Así, como la ausencia del Estado debe mostrar una coresponsabilidad en los escenarios alternativos de justicia.

No es posible buscar soluciones de tipo individual excluyendo los contextos de violencia generalizada y de marcada ausencia institucional, así como elevados márgenes de corrupción. No es posible percibir un modelo transicional de justicia enfocado en un examen de seguridad material o de cifras, pues de debe ahondar hacia las raíces del conflicto armado interno.

Repensar la justicia tiene que ver con asumir las condiciones socio-históricas particulares del territorio y la población destinataria. Es hora de pensar la justicia transicional dentro del marco de un cambio radical en el orden social y político (Uprimny y Lasso, 2004) para la construcción de un nuevo escenario de regulación social en el que ya no primen las diversas gamas de violencia como forma de solución de conflictos.

Reflexionar sobre los retos que propone la justicia transicional a los modelos de justicia tradicionales, nos permite comprender la estructura de lo que llamaremos el dilema colombiano.

Un dilema que se pierde entre el juicio moral y sobre un diagnóstico de las condiciones en las que están dados los conflictos. El dilema colombiano borra la distinción entre guerra y conflicto y dibuja sus sistemas de justicia sobre la base de una idea del enemigo social que resulta profundamente peligrosa para el desarrollo de una sociedad en paz. Pensar los retos que se deberían asumir para un modelo de justicia transicional resulta imprescindible y necesario en tiempos de crisis.

Para pensar este problema el artículo se divide en cuatro partes: 1) revisión del planteamiento de Ruti Teitel a propósito de una lectura genealógica del concepto de justicia transicional. 2) revisión de los modelos de justicia transicional analizando la naturaleza de sus conflictos armados internos y sus posibles formas de comprensión. 3) contextualización del proceso de paz con las Fuerzas Armadas Revolucionarias de Colombia-EP y, 4) exponer los principales retos sociales que plantea el marco alternativo de justicia particular, atendiendo a las condiciones específicas del conflicto colombiano.

\section{UNA GENEALOGÍA DEL CONCEPTO DE JUSTICIA TRANSICIONAL}

El trabajo Transitional Justice Genealogy (2003) de la profesora Ruti Teitel se puede explorar la posible genealogía del concepto justicia transicional, 
The origins of modern transitional justice can be traced to World War I. However, transitional justice becomes understood as both extraordinary and international in the postwar period after 1945. The Cold War ends the internationalism of this first, or postwar, phase of transitional justice. The second, or post-Cold War, phase is associated with the wave of democratic transitions and modernization that began in 1989. Toward the end of the twentieth century, global politics was characterized by an acceleration in conflict resolution and a persistent discourse of justice throughout law and society. The third, or steady-state, phase of transitional justice is associated with contemporary conditions of persistent conflict which lay the foundation for a normalized law of violence (Teitel, 2003, p. 70).

Esta caracterización nos da algunas pistas para comprender las múltiples condiciones en las que se gestan los conflictos. El concepto de justicia transicional no es una aparición reciente, sino que ha estado en el marco de las discusiones del siglo XX como formación que pretende encarar la relación entre justicia y guerra.

La división en tres fases de esta genealogía nos ayuda a comprender el marco de inteligibilidad en el que es posible hablar de justicia transicional. La primera fase que está ubicada en el periodo entre guerras, es clave para entender que, el término justicia transicional, es producto de dichas relaciones entre la anhelada justicia y la feroz guerra.

Para hablar de justicia transicional se debe reconocer, entonces, la existencia de un conflicto bélico entre dos actores en cuyas acciones hay una serie de violaciones a los derechos humanos y a la soberanía de un territorio, en esta primera fase - tal y como lo señala la profesora Teitel - se trata de la intervención de una figura internacional en el marco de un conflicto que compromete a una o más naciones; los juicios de Núremberg, lograron establecer así responsabilidades dentro del marco de las acciones bélicas y contribuyeron al desarrollo de pensar la universalidad de la ley en el marco de las acciones bélicas.

Sin embargo, según la autora es necesario pensar que este es un modelo de posguerra con bastantes problemas. Exclusivo de administración de justicia en tiempos excepcionales y posteriores a los escenarios bélicos, permitió implementarse en el derecho internacional como una salida a las particularidades del derecho intra-estados. Veamos:

In the postwar phase, the exportation of forms of transitional justice occurred through legal transplants of treaties, conventions, and constitutionalism. The postwar period was also the heyday of the belief in law and development, and more generally in the belief in law as a tool for state modernization (Teitel, 2003, p. 74).

Este aspecto paradójico de comprensión de la ley como herramienta de modernización del Estado demuestra que la cuestión de la justicia no es una cuestión únicamente punitiva, en ese sentido es la fase II del estudio de Teitel, expone esa reconfiguración del modelo de Justicia transicional.

Lo que sucedió tras el desarrollo de la posguerra fue la necesidad de pensar cómo tramitar acciones de guerra fuera de los marcos jurídicos de la soberanía nacional, ese reto fue fundamental para pensar las relaciones entre Estados más allá de los marcos que se habían establecido.

La segunda fase de la genealogía trazada por Teitel se ubicó tras la caída de la Unión Soviética como proyecto globalizador y, por lo tanto, el desmantelamiento de la idea de un mundo regulado por dos ideologías imperantes, esto, es para Teitel, el escenario de una transición democrática y el fin del modelo de los Estados autoritarios.

En medio del desarrollo de los llamados nuevos Estados democráticos tanto en Europa del Este como en América Latina, surgieron una serie de preguntas sobre el cómo juzgar a aquellos dictadores que hicieron parte del juego estratégico de dominación o cómo juzgar a las partes 
insurgentes que jugaron papeles determinantes en el desarrollo de la guerra, así señala Teitel la diferencia entre las fases I y II del modelo de justicia transicional:

In this regard, international legal norms serve to construct a perception of continuity and consistency in the rule of law. The profound and permanent significance of the Nuremberg model is that by defining the rule of law in universalizing terms, it has become the standard by which all subsequent transitional justice debates are framed. Whereas the Phase I justice policy simply assumed the legitimacy of punishing human rights abuses, in Phase II the tension between punishment and amnesty was complicated by the recognition of dilemmas inherent in periods of political flux" (Teitel, 2003, p. 76).

La fase II de la genealogía tiene la particularidad de reconocer el conflicto, no como un juego de vencedores y vencidos, sino como un desarrollo complejo de relaciones políticas que recurren a la guerra como una forma de construcción política, en ese sentido, el modelo de la fase II reconoce que los conflictos bélicos atienden a contenidos que requieren una mejor comprensión de los dilemas y las paradojas que van dando forma a los conflictos, así:

"Transitional jurisprudence was linked to a conception of justice that was imperfect and partial. What is fair and just in extraordinary political circumstances was to be determined from the transitional position itself. Accordingly, multiple conceptions of justice emerged in Phase II" (Tetiel, 2003, p. 76).

La emergencia de nuevos discursos y formas de comprensión de la justicia obedece, como bien lo dice Teitel a un reconocimiento de la ley, no como un mecanismo de modernización del Estado, sino como el desarrollo de una idea imperfecta y parcial que es necesario pensar constantemente.

Esa idea que se deriva de la comprensión de la justicia como imperfecta y reglada por las diferentes posiciones en diferentes contextos será clave para entender la naturaleza de un proceso transicional, de manera que la ley no se entienda como la acción de una soberanía extralimitada, sino como el proceso de constitución de una acción política tendiente a la construcción de garantías para cesar los conflictos bélicos.

Uno de los puntos clave para esta transformación del modelo de la justicia transicional tiene que ver con la naturaleza misma de los conflictos, ya no se trata solo de cesar el conflicto, sino de comprender las causas del mismo dentro de los marcos bélicos. Se trata también de visualizar lo que vendrá después del cese de los conflictos de manera que esto nos permita pensar en la consolidación posterior del Estado. En palabras propias de Teitel:

The transitional dilemmas at stake in Phase II were framed in terms more comprehensive than simply confronting or holding accountable the predecessor regime, and included questions about how to heal an entire society and incorporate diverse rule-of-law values, such as peace and reconciliation, that had previously been treated as largely external to the transitional justice project. Accordingly, the move away from judgment associated with international justice reflected a shift in the understanding of transitional justice, which became associated with the more complex and diverse political conditions of nation-building (Teitel, 2003: 77).

La incorporación de estas dimensiones hace que el campo de inteligibilidad de la justicia transicional sea más amplio, ya que no se trata solo de juzgar a quienes cometieron violaciones a los derechos humanos, sino de comprender cómo es que este tipo de conflictos de naturaleza bélica, surgen y se mantienen en el tiempo, a punto de normalizarse.

En ese orden de ideas, en la segunda fase del modelo transicional existen dos tensiones: 1 . La primera tensión se presenta en la yuxtaposición verdad y justicia, y; 2. Una segunda tensión en la ecuación justicia y paz. Esas dos tensiones marcan de manera definitiva la comprensión de la justicia transicional, pues lo que está en juego tiene que ver con la construcción de una sociedad en paz, no con el juzgamiento de actores al interior del conflicto como en la fase I. 
Esa doble tensión que se impregna en los conflictos armados internos de las últimas décadas del siglo XX, expone que la cuestión de la justicia transicional es un fenómeno complejo en el que se cruzan acciones de construcción de tejido social como la historia, la memoria y la reconciliación, etc. No se trata exclusivamente en la cesación del conflicto bélico sino de ver cómo es que este se configuró, qué voces silenció, bajo qué racionalidad operó y de qué forma es posible reconstruir ese tejido social que se quebró con el accionar de violencia. En ese sentido la instauración de mecanismos como las comisiones de la verdad son definitivas en materia de construcción de paz.

Por otro lado, reconocer la verdad del conflicto armado interno implica necesariamente, hacer una apuesta donde la justicia cede en función de la paz. Un noble reemplazo restaurativo que puede parecer alejado de los conceptos de la justicia ordinaria.

En este proceso se trata de pensar el problema como un proceso de reconciliación a mayor escala, donde esa doble tensión entre verdad y justicia y entre justicia y paz, se convierte en esencial para la consecución de espacios de rehabilitación posbélica, donde los restos también son dobles: silenciar los fúsiles y producir garantías de no repetición.

Finalmente, en la genealogía adelantada por Teitel, se identifica una tercera fase en la que el problema de la justicia transicional se desplaza de la periferia al centro. A finales del siglo $\mathrm{XX}$, el modelo de la justicia transicional ya no será solo mentado desde los pequeños conflictos que se derivan de situaciones específicas, sino que será pensada de manera constante para la consolidación de Estados estables. Consolidándose con la creación de cortes internacionales son jurisdicción subsidiaria, como la es el caso, de la Corte Penal Internacional.

Sin embargo, el desplazamiento del discurso de justicia transicional de la periferia al centro, puede resultar peligroso en la medida en que se politiza de manera fuerte la ley y que, so pretexto de un horizonte humanitario, el conflicto armado se puede recrudecer:

The expansion of the transitional justice discourse to the issue of terrorism proves problematic due to the inadequacy of the analogies between terrorism and war or political crisis. Transitional justice tends to look backward in responding to the last conflict, and therefore it does not adapt easily to use as a template to guarantee prospective security. Any attempt to generalize from exceptional post-conflict situations in order to guide politics as a matter of course becomes extremely problematic (Teitel, 2003, p. 92).

El modelo genealógico nos deja dos conclusiones parciales que son claves para el desarrollo de la argumentación subsecuente:

1. Expone que la cuestión de la justicia transicional proviene del conflicto bélico del Siglo XX y que ha estado sometida a una serie de debates durante cambios esenciales en la forma de comprensión de la guerra y del conflicto durante cerca de medio siglo. En esa medida, no existe un solo concepto de justicia transicional, ni existe un solo mecanismo para llevarla a cabo, lo que sí resulta importante pensar en ese mapa de la disputa, es que para que exista un proceso de justicia transicional, existen unos entes reguladores en los que está de facto proteger los derechos humanos y frenar la confrontación armada como acto de manifestación política.

2. Tras el concepto de justicia transicional hay una serie de disputas políticas y sociales; uno de los mayores riesgos es el de politizar la ley en virtud de un proceso de privatización para beneficiar a uno de los actores al interior de una guerra, esto implica que para llevar a cabo un ejercicio de justicia transicional sea necesario reconocer la contingencia y la historia del conflicto de manera que sea posible tensar la relación entre justicia y paz para desde allí pensar la mejor forma de transición posible. 


\section{ANTECEDENTES: MODELOS DE JUSTICIA TRANSICIONAL EN EL MUNDO}

Es necesario aclarar, tal y como lo señalan Uprimny y Lasso (2004) que, los modelos de justicia transicional no son modelos que se puedan trasladar de un lado a otro, coincidiendo en la partida con Teitel (2003), pues cada conflicto tiene en sí mismo una serie de condicionamientos específicos, contingentes y que le pertenecen a la historia de ese conflicto en particular, en esa medida no es posible globalizar un modelo de justicia transicional, ni mucho menos pretender crear una fórmula acertada para el desarrollo de cualquier proceso.

Comprender que la justicia es siempre imperfecta es una cuestión clave en este campo. Sin embargo, bien lo señala Uprimny (2006) es posible clasificar de manera básica y en función de su contenido, algunos modelos de justicia transicional que han tenido lugar.

El modelo expone una clasificación a través de contenidos, en esa medida, denota que han existido al menos cuatro formas distintas de llevar a cabo procesos de justicia transicional y que ellos han variado de acuerdo a las circunstancias particulares de los conflictos. Los modelos I y IV son para Uprimny modelos radicales, que si se observan con detenimiento pueden parecer procesos de justicia que no contienen en sí mismos el cambio de orden social o político para la terminación del conflicto. Son procesos que atienden a cerrar la contienda, pero no a dar terminación de sus raíces, es decir, a esa serie de conflictos que quedan abiertos y que no se pueden tramitar con indultos o con penas de cárcel de manera exclusiva.

Por otro lado, están los modelos intermedios: II y III. En ellos los que se persigue es comprender la emergencia de la guerra y reparar a las víctimas con el fin de individualizar responsabilidades, buscar memoria histórica y producir garantías de no repetición. No se trata de castigar ni de perdonar los crímenes atroces para dar un tránsito a un estado de paz, sino de comprender que la paz es un proceso que solo puede ser fructífero tras la comprensión de las causas, de las estructuras y de los móviles que convirtieron las formas de tratamiento de los conflictos en actos de guerra.

Uprimny (2006) igualmente clasifica los procesos transicionales por la forma que asumen en el desarrollo de su adopción, reconociendo cuatro modelos que se han llevado a cabo en procesos transicionales en el mundo.

Es necesario aclarar que estos modelos son también ideales y que lo que ha ocurrido en la mayoría de procesos de transición es una mezcla entre los modelos de forma y de contenido. Esto nos permite indicar que la justicia transicional es dinámica y que no tiene unos estándares siempre precisos ni en los contenidos, ni en las formas, serán los acuerdos políticos los que construyan ese conjunto de relaciones y determinen los tiempos de esas estructuras.

Uprimny (2005), señala que para el caso colombiano sería pertinente usar el modelo IV de transiciones democráticamente legitimadas. Las experiencias de Sudáfrica e Irlanda del Norte, adoptaron modelos de transición democráticamente legitimados tal y como aconteció para la aprobación del proceso de paz con las Farc-EP. Veamos. 


\section{EL CASO DE IRLANDA DEL NORTE: AGENDA Y CONSTRUCCIÓN DE PAZ}

Existen al menos dos particularidades compartidas con el caso de Irlanda del Norte que son claves para entender el modelo del proceso de paz con las Farc-EP: la duración y características históricas del conflicto.

La duración del enfrentamiento armado en Irlanda del Norte fue de cerca de 30 años desde mediados de 1970 y hasta la firma del acuerdo en 1998. Por otro lado, una de las causas principales de este conflicto obedeció a la marginación y la creciente desigualdad económica que se generó por una profunda división religiosa entre protestantes y católicos, en la que los católicos llevaron la peor parte. Diferencia de religiosa y económica que se extendió hasta la producción del levantamiento en armas que desató diversas problemáticas asociadas a los conflictos políticos complejos.

El caso de Irlanda del Norte es ejemplar en la forma de la transición porque impuso un principio en la negociación que resultó pragmáticamente útil: "nada está acordado hasta que todo este acordado". Principio decisivo para entender que los conflictos producidos no se tratan de manera diferencial, sino que hacen parte de un conjunto complejo y de una trama histórica que se puede diferenciar gradualmente para el tratamiento, pero que cada parte tiene igual importancia. Un manejo integral del conflicto y sus causas.

Otro de los elementos claves en el proceso de negociación de paz, tuvo que ver con el desarrollo de tres ejes diferenciales:

- Relaciones endógenas;

- Relaciones en la isla de Irlanda: República de Irlanda (Irlanda del Sur) e Irlanda del Norte.

- Relaciones entre Reino Unido y la República de Irlanda.

Esta estructura del acuerdo permitió el desarrollo de uno de los mayores logros en materia de justicia transicional:

Dividir las discusiones de paz en distintas comisiones, cada una con un tema específico y entre tantas partes, suponía el reto de elaborar un acuerdo final a partir de las conclusiones de diferentes mesas de discusión en las que los participantes planteaban con regularidad una serie de inamovibles. Ese es quizás uno de los mayores logros del Acuerdo de Viernes Santo de 1998, que puede ser explicado si se tiene en cuenta el enorme grado de inclusividad que poseían las negociaciones, al igual que la construcción de una confianza y un lenguaje comunes (Mantilla, 2014, p. 3).

Parte de la clave en la construcción de un acuerdo que tiene como intención el tránsito del conflicto armado hacia a la paz, tiene que ver con la construcción de un lenguaje común. Quizá este sea el punto más complejo de las discusiones en las mesas de negociación y la tarea más difícil cuando se trata de buscar un tratamiento justo frente a la tensión que se presenta entre las ecuaciones: justicia y paz - justicia y verdad.

El modelo de división de agendas en la discusión resultó ser uno de los elementos que el acuerdo de con las FARC-EP retomó de la agenda de Irlanda del Norte, procurando que en ese esquema se diera trato diferencial, pero integral a cada uno de los conflictos que había generado la guerra.

Asimismo, el Acuerdo de Viernes Santo enfatizó en la necesidad de reconocer el sufrimiento de las víctimas, de manera que, desde allí se parta hacía un verdadero ejercicio de reconciliación y de construcción democrática.

En este movimiento la sociedad civil tuvo un importante papel, tal y como lo señaló Mantilla: 


\begin{abstract}
Sir Kenneth Bloomfield fue designado comisionado de víctimas de Irlanda del Norte para elaborar, entre otros, un informe sobre la aplicación de la justicia transicional que se denominó Las recordaremos. Para cumplir con dicha tarea de evaluación, se realizó una convocatoria masiva a través de diferentes medios de comunicación, solicitando información acerca de la percepción general sobre el tratamiento dado a las víctimas del conflicto armado, y sugerencias acerca de las formas de reparar el daño sufrido por ellas, propiciando a su vez el ambiente más apropiado para la reconciliación. La respuesta a esta convocatoria fue masiva, y se hicieron partícipes, entre otras, la población norirlandesa, organizaciones no gubernamentales y entidades privadas $(2014$, p. 5).
\end{abstract}

Establecer canales de comunicación con la sociedad civil permitió que el proceso de transición funcionara de manera integral. Este modelo estuvo acompañado de varias campañas internacionales para garantizar condiciones mínimas y mitigar las causas estructurales que configuraron los conflictos como la segregación social y económica. Se buscó cesar la violencia, pero también construir escenarios para que las causas estructurales del mismo no volvieran a emerger.

La lección es clara: la agenda de negociación es un proceso de transición que depende de la sociedad en su conjunto, sin embargo, el hecho que dos actores antagónicos decidan cesar su confrontación es una prueba clara de que hay otros horizontes, quizá más democráticos, para poder solucionar conflictos internos. Finalmente, el modelo de justicia transicional de Irlanda del Norte fue efectivo gracias al desarrollo de un arreglo institucional que logró prescindir de las diferencias y entender la paz como un modelo de superación de incompatibilidades (Mantilla, 2014, p. 12).

\title{
5. EL CASO DE SUDÁFRICA: COMISIÓN DE LA VERDAD Y LA JUSTICIA
}

El caso sudafricano contiene una cantidad de variables complejas, no solo por el añadido de la violencia racial que contrae su conflicto, el cual tiene unas variables históricas, económicas y una deuda histórica que daría para pensar con cuidado durante mucho tiempo, sino porque la naturaleza del conflicto tiene algunas variables como el cierre de la participación política, los profundos grados de desigualdad y el uso de la violencia como forma de resolución de conflictos que, resultan pertinentes para pensar el problema de un modelo de justicia transicional.

Sudáfrica se centró en el desarrollo de indultos a todos aquellos crímenes que tenían que ver con acciones de guerra por motivos políticos, quedando claro así en el acuerdo de 1993:

In order to advance ... reconciliation and reconstruction, amnesty shall be granted in respect of acts, omissions and offences associated with political objectives and committed in the course of the conflicts of the past. To this end, Parliament under this Constitution shall adopt a law determining a firm cut-off date, which shall be a date after 8 October 1990 and before 6 December 1993, and providing for the mechanisms, criteria and procedures, including tribunals, if any, through which such amnesty shall be dealt with at any time after the law has been passed (Interim Constitution of the Republic of South Africa, 1993).

Basado en la idea de una confesión de los crímenes de quienes acudieran a la Comisión de la Verdad y, posteriormente, al Comité para Amnistías, encontraban la posibilidad de obtener un indulto independiente de las formas de violencia que, se hubiesen presentado en el apartheid.

Ese modelo de construcción de una comisión de la verdad tensó la relación entre verdad y justicia de una forma que representó un peligro especial, tanto para las víctimas, como para el ejercicio de reconciliación.

La idea de que al obtener "toda" la verdad del conflicto será posible generar una serie de condiciones para la no repetición de los crímenes y para el desarrollo de un impulso de no venganza generó una serie de preguntas en torno a lo que se debe decir y no decir, sobre lo que se debe 
perdonar y lo que no, e incluso, sobre lo que es la memoria histórica en este proceso de construcción de verdad y lo que no.

La tensión entre estos tres elementos, perdón, verdad y justicia es una clave que debe poder solventarse de manera efectiva, no solo para cesar los muertos al interior de un conflicto, sino para poder construir escenarios reales de transición en los que exista un decidido compromiso con la no repetición.

El modelo de la Comisión de la Verdad sudafricano trajo consigo incluso un margen de impunidad:

[...] la oferta de "amnistía por verdad" hecha a los autores de violaciones de los derechos humanos que estaban dispuestos a confesar sus crímenes por parte de la CVR, generó una impunidad que hasta el día de hoy produce inquietud, dados los pocos enjuiciamientos de personas involucradas en crímenes contra los derechos humanos en la última década. Sólo en 1996 tuvo lugar el juzgamiento del antiguo comandante del Vlakplaas Eugene de Kock (Rodríguez, 2011, p. 58).

Privilegiar una verdad sin más puede convertirse en una forma de re-victimizar sin conceder la posibilidad de restaurar o de reconciliar el tejido social que se había interrumpido por el desarrollo del conflicto armado. Esto no implica desconocer el valor de la comisión de la verdad como aparato clave para entender qué pasó en el conflicto, sino que se expone la necesidad de usar otros mecanismos que permitan movilizar acciones más contundentes para la reconstrucción de lo que ha quedado en ruinas:

Si bien la Comisión de Verdad y Reparación obró una importante labor en la condena moral del apartheid y en la instalación de un ideal de reconciliación en un pueblo dividido por decenios, la capacidad para traducir este pensamiento en una mejora sustancial de las condiciones objetivas de la población ha sido más bien reducida (Rodríguez, 2011, p. 58).

Las lecciones del caso sudafricano: la idea de un diálogo entre víctimas y victimarios fue clave para generar escenarios de reconciliación, así como, garantía de la comisión de la verdad para construir memoria histórica.

\section{PAZ, JUSTICIA Y VERDAD EN COLOMBIA}

La historia de Colombia, puede decirse de una u otra manera, ha sido la historia de los procesos de paz. El culminado proceso con las Farc-EP en 2016, es uno dentro de los múltiples que se han llevado a cabo en el territorio nacional con el fin de acabar los enfrentamientos con el Estado por 70 años, con prácticas sistemáticas de desaparición forzada, secuestros, torturas, reclutamiento de menores, violencia sexual como arma de guerra, desaparecidos, asesinatos, etc. Un conflicto armado interno dotado múltiples factores y disímiles explicaciones.

Se ha escrito que el conflicto se desató por una diferencia ideológica entre conservadores y liberales y que se agudizó sobre la base del uso de la violencia por parte de esas autodefensas campesinas que luego se constituyeron como guerrillas insurgentes; también se ha dicho que es a causa del abandono del Estado, sobre todo si atendemos las brechas de lo urbano y lo rural así como la diversa geografía colombiana; igualmente se ha dicho que se consolidó el conflicto por el matrimonio funesto de tierras y narcotráfico, multiplicando las formas de violencia. 
Los actores de este fresco son muchos: guerrillas armadas, ejércitos privados, bandas criminales, estructuras paramilitares, financiadores de la guerra, políticos, narcotraficantes, y fusiones entre ellos y actores exógenos ilegales, etc.

Uno de los principales problemas ha sido moralizar el diagnóstico del conflicto armado interno. Las Farc-EP, fue posicionado con el gran culpable de la violencia en Colombia, disipando el resto de amenazas, muchas latentes en 2020. En ese juego es un error moralizar el debate y perseguir un culpable, todos y cada uno de los actores tiene un grado de responsabilidad en el conflicto interno armado y, en esa medida, la tensión entre justicia y verdad se tensará de manera definitiva.

Han sido varios los intentos fallidos que se han emprendido con el ánimo de consolidar un escenario de paz y de transición en Colombia, incluso arreglos institucionales como el Frente Nacional estuvieron diseñados para cesar el rugir de los fúsiles y ofrecerle a la ciudadanía un Estado en paz. Entre los múltiples errores cometidos se resalta como fundamental a la falta de garantías del Estado, así como, desarrollar esfuerzos efectivos para la producción de la verdad que involucre a todos los implicados de forma directa o indirecta del conflicto armado interno.

La historia de los espacios de transición en el país empieza con la amnistía a las guerrillas liberales en 1953. El proceso permitía a los campesinos organizados en guerrillas en los campos la posibilidad de reintegrarse a la vida civil, sin embargo, a este proceso de amnistía se siguió una serie de asesinatos selectivos a los líderes de las guerrillas, desarticulando al movimiento y creando un escenario para la perpetuación del conflicto armado. Con la muerte de Guadalupe Salcedo en Bogotá, este primer intento de transición quedó sellado, al no encontrar un balance entre justicia y paz lo suficientemente fuerte para el sostenimiento de un proceso de construcción de paz.

Un segundo intento de construcción de escenarios de transición fue el del Frente Nacional, como respuesta al apalancamiento en el poder de Rojas Pinilla y sus reformas, los principales líderes de los partidos conservador y liberal se la jugaron por una estrategia en la que se acordaba cesar la violencia bipartidista turnándose el poder cada cuatro años. El pacto de élites que se cerró en este momento demostró que un arreglo institucional sin el apoyo de la sociedad civil, o sin atender a las necesidades de la misma, no podía construir un escenario sólido para la cesación del conflicto como forma de expresión política. Por otro lado, el desarrollo del movimiento comunista en América Latina impulsó a una nueva ola de violencia de la que emergerían las guerrillas marxistas, una década después.

Con la ley 35 de 1982 el gobierno de Belisario Betancourt logró abrir un nuevo escenario de transición en la historia de la construcción de paz. Con su ley de amnistía cientos de insurgentes lograron salir de la cárcel y se creó un ambiente favorable para el desarrollo de un acuerdo. El 28 de mayo de 1984 se firmó en La Uribe un cese bilateral que traería consigo la posibilidad de la reincorporación a la vida civil de los combatientes de las guerrillas. Sin embargo, en dicho pacto no se trataron elementos sustanciales para el desarrollo de un escenario de transición como la entrega de armas o el tiempo en el que se adelantarían las reformas estatales para garantizar los derechos de los excombatientes.

El pacto de La Uribe dio como resultado la creación del partido político de la Unión Patriótica en el que se aglutinaban diferentes sectores de la izquierda, incluyendo a algunos combatientes de las Farc-EP, pero debido al relativo éxito de este partido en las elecciones de 1986, la amalgama paramilitar, institucional y narcotraficante, se dedicó exterminio a través de asesinatos selectivos con fundamento genocida. En la creación de este escenario de transición no fue posible tensar una relación lo suficientemente fina entre justicia y paz que permitiera consolidar la vida y la participación política de uno de los actores del acuerdo. 
Siguieron algunos procesos de transición que naufragaron violentamente como el diálogo nacional con el M-19, el EPL y la ADO, en el que no existieron condiciones para el tránsito a la vida civil. Serán los procesos de paz del M-19, EPL, PRT y Quintín Lame, los que resultaron en el desarrollo de la Asamblea Nacional Constituyente de 1990 y quienes representaron el desarrollo de una mejor relación en la tensión entre justicia y paz. Los modelos de indulto y el paso a la vida política que permitió la constituyente, marcaron un modo de producir escenarios de transición en Colombia y que resultó clave para el desarrollo del Acuerdo del Colón en 2016. No obstante, el asesinato de Carlos Pizarro en plena campaña electoral, sembró todas las dudas del futuro de la constituyente.

Dejemos claro que construir un escenario de transición no es una tarea fácil y que, tal y como lo dejó de lección el acuerdo en Irlanda del Norte, la paz tiene que ver con producir un modelo de superación de incompatibilidades. Un escenario de transición es fundamentalmente un espacio en el que bajo unos principios normativos se hace posible regular una situación atípica que está marcada por el desarrollo de un conflicto armado donde el uso de las formas de violencia es sistemático.

\section{EL MODELO DE LA JUSTICIA ESPECIAL PARA LA PAZ -JEP- Y EL CONTEXTO DE LA TRANSICIÓN}

El principal riesgo en 2020 que se corre en Colombia es el de la construcción de un balance pertinente entre justicia y verdad. De ese balance depende la construcción de una sociedad civil que pueda recomponer el tejido socio-histórico acudiendo a la memoria y gestando garantías de no repetición.

El principal reto que tiene la sociedad colombiana es, entonces, el de consolidar un área de transición triangular. La producción de esa área dependerá de un balance entre verdad, justicia y paz. El modelo de justicia transicional debe estar, entonces, comprometido con las víctimas, tenerlas efectivamente como centro del desarrollo de la transición, de manera que su movilización lleve a consolidar la justicia como un derecho que permita conocer la verdad y la complejidad del conflicto, a través de la JEP.

Para poder sostener una tensión fructífera entre verdad y paz resulta decisivo atacar los problemas estructurales que originan, en este caso, el conflicto particular con las Farc-Ep. No puede existir verdad y paz sin instituciones fuertes, sin el acercamiento de los rural y lo urbano, la construcción de la memoria histórica y garantías de no repetición.

La JEP propone durante un periodo de 15 años juzgar a aquellos excombatientes de las Farc-EP que hayan firmado el acuerdo y tenido participación directa o indirecta en el desarrollo del conflicto interno armado. La JEP es clara en dejar en manos de la justicia ordinaria a aquellos combatientes que no se acogieron al proceso de paz y frente aquellos que incumplan lo acordado.

El mecanismo está diseñado dentro del marco de la tensión entre justicia y paz y tiene como campo de inteligibilidad el desarrollo de un ejercicio de reconciliación, por lo tanto, sus tres principales pilares son:

1. Satisfacer el derecho de las víctimas a la justicia

2. Ofrecer verdad a la sociedad colombiana

3. Contribuir al logro de una paz estable y duradera 
Se trata de un mecanismo de justicia transicional que actuará en la construcción de un espacio que mantenga clara la tensión entre justicia y paz, no de arriesgar la una por la otra, sino de mantener en virtud de la producción de un espacio de reconciliación, los elementos fundamentales para ello. Los delitos excluidos de la JEP tendrán que responder ante la justicia ordinaria

Además, se estableció en el acuerdo la creación de 4 mecanismos transitorios para el desarrollo del propósito transicional:

- Comisión para el esclarecimiento de la Verdad, la Convivencia y la no repetición.

- Unidad de Búsqueda de personas dadas por desaparecidas en el contexto del conflicto armado,

- Jurisdicción Especial para la Paz,

- Medidas de Reparación Integral y las garantías para la no repetición.

No se trata solo de amnistiar a los excombatientes, sino de entender qué fue lo que sucedió en el conflicto y para ello, el desarrollo de la JEP y de la Comisión de la verdad, resultarán decisivos para el triunfo de la implementación de los Acuerdos del Colón.

Finalmente, para mantener la tensión entre verdad y paz será necesario que la justicia no quede restringida a un modelo punitivo, sino que los victimarios asuman su responsabilidad y entreguen condiciones para la reparación de las víctimas, en este sentido el Estado arreglará una serie de condiciones institucionales para que la reparación bien sea simbólica o física se realice de manera efectiva. No se trata solo de contar la verdad, sino de mantener una tensión entre lo que sucedió y la voluntad de construcción de paz que es necesaria para el desarrollo de un país mejor. Se trata de que de la transición pueda emerger un modelo de justicia restaurativa que pueda mantener vivas las tensiones que un conflicto de esta magnitud expone y que son parte constitutiva de ese modelo triangular.

\section{JUSTICIA RESTAURATIVA EN COLOMBIA}

El conflicto interno armado colombiano es fenómeno estructural que afecta la vida cotidiana de las personas en sus diferentes dimensiones económica, política, social y cultural, que ha generado la construcción de diferentes miedos que impiden el empoderamiento de los actores. Uno de esos actores es las Farc-Ep.

La lógica institucional del Estado por homogeneizar las condiciones y necesidades de las comunidades territoriales, propone retos para reestablecer las condiciones de vida y resarcir los daños causados, reconociendo la pluridiversidad de discursos, emociones y acciones que, los actores generan en cada contexto. No existen recetas uniformes para ello.

Las comunidades son quienes deben resolver con sus propias metodologías los conflictos atendiendo a sus demandas y necesidades particulares. Por esto se justifica el detrimento de las medidas punitivas de justicia en pro de soluciones restaurativas.

Los escenarios locales de participación algunas veces responden solo al ámbito institucional, concejalías, edilatos o alcaldías, desconociendo muchas formas de asociación comunitaria como las juntas de acción comunal, los gremios y las organizaciones sociales. Ante este panorama, solo la vinculación de los actores sociales puede permitir la construcción, implementación y evaluación de las metodologías restaurativas a través de escenarios participativos. De acuerdo a las Naciones Unidas un proceso restaurativo es todo aquel en donde "la víctima, el delincuente y... cualesquiera 
otras personas o miembros de la comunidad afectados por un delito participen conjuntamente de forma activa en la resolución de las cuestiones derivadas del delito, por lo general con la ayuda de un facilitador" (2006, p. 7).

La justicia restaurativa se establece como un mecanismo alterno de justicia centrado en las víctimas, la comunidad y la responsabilidad del infractor, quien se constituye en agente del proceso restaurativo.

Los procesos de justicia transicional requieren que se genere respeto por las víctimas a través de estrategias de sensibilización, pues dicho contexto puede incubar otras situaciones o problemas que se pueden reflejar en los diferentes territorios donde se implementan los acuerdos de paz. Uno de ellos se centra en la posibilidad de encontrar escenarios de reconciliación entre víctimas y victimarios a través de la justicia restaurativa, siguiendo a Uprimny y Saffon (2005):

"en términos generales, la justicia restaurativa se presenta como un modelo alternativo de enfrentamiento del crimen que, en lugar de fundarse en la idea tradicional de retribución o castigo, parte de la importancia que tiene para la sociedad la reconciliación entre víctima y victimario (pp. 217-218)”.

Por lo tanto, las relaciones que surjan entre víctimas y victimarios deben propender por medidas pedagógicas que afiancen relaciones de alteridad donde el reconocimiento del otro sea una prioridad. Esta premisa trae consigo una trasformación cultural en la resolución de los conflictos donde las medidas punitivas son transformadas por la recuperación del daño causado y el fortalecimiento del tejido social, como práctica voluntaria donde los actores sociales asumen su protagonismo y corresponsabilidad, según Naciones Unidas (2006):

"Los programas de mediación víctima-delincuente (también conocidos como programas de reconciliación víctima-delincuente) estaban entre las primeras iniciativas de justicia restaurativa. Estos programas están diseñados para abordar las necesidades de las víctimas del delito, asegurándose de que los delincuentes sean hechos responsables por sus delitos. Los programas pueden ser manejados por instituciones gubernamentales y organizaciones sin fines de lucro, y están generalmente restringidos a casos que implican delitos no muy graves (...) Los sujetos se empoderan y toman decisiones sobre su propia situación (Naciones Unidas, 2006: 17)”.

Diana Britto (2010), considera que la justicia restaurativa es "un tipo de justicia centrada en la dimensión social del delito. Busca restaurar el lazo social dañado por la acción criminal en un proceso de reparación y reconciliación entre la víctima y el infractor, con la mediación de la comunidad".

La justicia restaurativa permite revisar distintos enfoques que facilitan al individuo vivir o convivir en sociedad, a través del uso de los principios de la imparcialidad del mediador, la confidencialidad del proceso de diálogo y la voluntariedad de ambas partes que deben participar por decisión propia, sin ser influidos o presionados externamente. El país está perfilado para generar procesos de participación amplios donde las víctimas y victimarios logren su empoderamiento a través de la toma de decisiones y la vinculación en el desarrollo de sus propias vidas ante escenarios adversos y dramáticos relacionados con la falta de voluntad política de la clase dirigente que podría corromper estas construcciones de confianza mutua en los territorios y la aplicación de metodologías restaurativas. De acuerdo a lo planteado por Britto:

"La justicia restaurativa representa un cambio en el paradigma retributivo. Con la justicia restaurativa se busca introducir un nuevo espíritu a la justicia, recrearla desde la perspectiva de las víctimas como protagonistas para que junto con el infractor y con el apoyo de la comunidad, se busque la reparación de los daños y la restauración de las relaciones de ambos con la sociedad (2010, p. 19)". 
Por lo tanto, se debe hacer a un lado la censura moral del contrincante y no se puede descalificar su contexto y propia realidad. La propuesta metodológica víctima - victimario definida desde la justicia restaurativa puede garantizar elementos para reparar el daño causado a través del análisis causal del conflicto, la reconstrucción de la memoria colectiva, el vínculo entre las partes y la transformación de la situación inicial. Esta estrategia inicial permitirá la aplicación de otras alternativas para reparar los daños causados a los actores en los distintos territorios, tal como ocurre con los círculos de discusión o sentencia.

Los círculos de discusión o sentencia como estrategia metodológica, surgen como un elemento transformador de justicia que involucra a las comunidades en la posibilidad de lograr la reinserción social de los actores involucrados en el delito o la infracción que permite reconocer la condición humana de los sujetos a través de la posibilidad de encontrar argumentos antagónicos y diversos entre las partes. En este sentido, retomamos la propuesta de Naciones Unidas (2006, p. 22) cuando afirma que:

"En las sentencias en círculo todos los participantes, incluyendo el juez, el consejero de la defensa, el fiscal, el oficial de policía, la víctima, el delincuente y sus familias respectivas, sus residentes comunitarios, se sientan frente a los demás en un círculo. Las sentencias en círculo están generalmente disponibles solamente para aquellos delincuentes que se declaran culpables. Las discusiones en el círculo están diseñadas para llegar a un consenso sobre la mejor manera de resolver el conflicto y disponer el caso, tomando en cuenta la necesidad de proteger a la comunidad, las necesidades de las víctimas y la rehabilitación y castigo del delincuente".

Este tipo de iniciativas requiere eliminar el imaginario de amigo/enemigo para centrar la discusión dialéctica que propone un escenario de adversarios que parten de la diferencia para poder dialogar y encontrar la solución a los antagonismos, es decir, construir escenarios que olviden las pequeñas rivalidades para agrupar a las comunidades en torno a intereses solidarios en defensa de interés colectivos. Según Britto, los objetivos de los círculos de discusión son:

\footnotetext{
"Promover la sanación de todas las partes afectadas, dando oportunidad al ofensor para reparar. Empoderar a las víctimas, ofensores, miembros de las familias y comunidades a través de su palabra y responsabilidad compartida para hallar soluciones constructivas, tejiendo un sentido de comunidad alrededor de los valores culturales de ésta fomentando nuevos valores culturales a partir del hecho. Identificar las causas de la conducta criminal. Construir sentido de comunidad y capacidades para la resolución de los conflictos. Y promover valores de paz (2010, pp. 41-42)".
}

Bañol y Bañol (2006) mencionan que la mediación y la conciliación no producen ganadores y perdedores, es un proceso cooperativo y de colaboración, donde no se busca la individualización de un culpable sino la recuperación de un sujeto para la sociedad.

Un cambio del plano legal hacia estrategias centradas en la construcción de escenarios de paz locales. Tal como lo mencionan Pérez y Zaragoza (s.f):

"Estos métodos restaurativos se diferencian de la Mediación Víctima-Ofensor en que involucran a más participantes, ya que no sólo participan la víctima y el infractor sino también las víctimas secundarias, como lo pueden ser familiares y amistades de la víctima, parientes y allegados del infractor, así como representantes del sistema de justicia penal (p. 644)".

En los procesos de construcción de justicia es necesario que los ciudadanos sean conscientes de su rol protagónico y se organicen colectivamente para blindar los métodos restaurativos de los enemigos de la paz que niegan la posibilidad de transformar la sociedad y recuperar el tejido social, donde no se respeta a las víctimas. Según Naciones Unidas "los procesos de justicia restaurativa pueden incrementar el compromiso con la comunidad y facilitan cómo los residentes 
de la comunidad se involucran en respuesta a la resolución de problemas de crimen y desorden social" (2006, p. 88).

La justicia restaurativa ha asumido y reflejado desde el inicio este debate y se ha comprometido con la doble misión de educar tanto la cabeza como el corazón, lo académico y lo emocional. Las acciones de trabajo comunitario reconocer las particularidades de los sujetos involucrados en procesos de justicia restaurativa donde se tenga en cuenta a los campesinos, indígenas y comunidades afrodescendientes. Se puede definir el trabajo comunitario como:

"el trabajo realizado por un ofensor en beneficio de la comunidad para reparar el daño causado por sus acciones. El servicio comunitario es más bien un resultado del proceso restaurativo, sin dejar de reconocer que puede tener un poder para rehabilitar al infractor" (Pérez y Zaragoza, s.f., p. 648).

A través del servicio a la comunidad el victimario observa los daños causados con quienes trabaja. Dimensionando nuevos límites de tolerancia social y le otorga un modo constructivo y proactivo de reparar los daños causados por su delito (Eliaerts, 2002).

El énfasis del servicio comunitario no está puesto en el castigo, ni en la rehabilitación. Se fundamenta no se centra "no en las necesidades de los delincuentes, sino en sus fortalezas; no en su falta de discernimiento, sino en su capacidad de ser responsables; no en su vulnerabilidad frente a factores sociales y psicológicos, sino en su capacidad de elección" (Wright,1991, p. 44).

\section{CONSIDERACIONES FINALES: RETOS DEL MODELO DE JUSTICIA TRANSICIONAL CON LAS FARC-EP}

Resulta importante anotar algunos de esos retos que, tanto a nivel conceptual, como a nivel práctico enfrentará Colombia en este proceso de transición. En primera medida, es necesario apelar a una distinción que resulta importante para marcar el terreno de la narrativa, es decir, el terreno en el que se producirá la verdad sobre el conflicto. La pensadora Chantal Mouffe ha insistido recientemente en la idea de que lo político es posible gracias a que el conflicto no se puede dirimir, esto, sin duda ha sido inspirado por pensadores de una tradición moderna del pensamiento como Spinoza, Maquiavelo y, más recientemente, por pensadores como Claude Lefort o Ernesto Laclau.

Este punto es importante porque si lo político tiene que ver con la imposibilidad de reducción del conflicto esto quiere decir que el conflicto no puede ser pensado dentro del marco de una regulación moral, es decir, el conflicto no es ni bueno, ni malo. Si atendemos a esta indicación, cuando hablamos de conflictos hablamos de una tensión de fuerzas que no se pueden vencer ni disolver.

Una tensión que siempre está presente en las relaciones sociales y que hace que la democracia sea posible como un escenario en el que se tramitan las diferencias. El primer reto requiere asumir esta postura de que el conflicto es irreductible, es decir, que siempre habrá tensiones, puntos de vista distintos, puntos en contraste y que para ello la política aparecerá como un mecanismo de gestión de conflicto.

Resulta necesario traducir el lenguaje y darle un lugar al conflicto interno armado como parte fundamental de nuestros desacuerdos, eso implica reconocer que el conflicto no es igual a la guerra, ni al uso de la violencia y que, tanto la guerra como la violencia física, tiene en su seno una lógica de supresión del conflicto.

Llámese como quiera, es vital despojarnos de la lógica de la guerra como supresión de lo otro diferente a mí y pasar a una lógica del conflicto donde pueda introducirme en el debate y superar a 
mi adversario en el marco del uso de la no-violencia. El pensador alemán Carl Schmitt en su Tratado político señaló que esta era la lógica en la que funciona lo político cuando logramos desmantelar la estructura de la relación amigo-enemigo y pasamos a la estructura de la relación adversarioadversario: un primer reto para la transición hacia una verdadera democracia.

El segundo reto que tiene que ver con la posibilidad de construir una institucionalidad que mantenga vivas las tensiones entre verdad-justicia-paz, que no pretenda dirimirlas, sino que opere en virtud de este esclarecimiento de manera constante, es decir, necesitamos de la presencia de un Estado que garantice la creación de espacios de transición, que cree mecanismos provistos para ese desarrollo y que, en ese orden de ideas, logre consolidar herramientas para que esas tensiones se mantengan.

Siendo necesario que estas reflexiones se incorporen en el cuerpo de la sociedad civil y que exista una reflexión mancomunada para el desarrollo de una transformación ética. La cohesión cultural y social en Colombia se ve amenazada por situaciones como la pobreza, el desempleo y la exclusión social. La disparidad urbana-rural no cesa.

El porvenir de la justicia restaurativa debe permitir que los diferentes actores víctimas, victimarios, comunidad y Estado, construyan las propuestas desde sus territorios como herramientas esenciales para solución de los conflictos, llevando a las personas a un mayor nivel de participación y toma de decisiones.

El Estado colombiano y sus instituciones deben reconocer la importancia de la justicia restaurativa para lograr verdaderos procesos de reconciliación a través de la verdad, la justicia, la reparación y la garantía de no repetición, teniendo en cuenta los actores locales y las dinámicas propias de los territorios.

\section{REFERENCIAS BIBLIOGRÁFICAS}

Arias, D. (2014). Relaciones internacionales (RRII) entre economías subterráneas o ilícitas (ESOI) narcoviolentas en Colombia y México y la incidencia de las políticas estatales de EEUU (1990-2014). $\underline{\mathrm{h}}$ ttp://www.iri.edu.ar/images/Documentos/doctorado/tesis/tesis_arias_henao.pdf

Bañol, A., y Bañol, L. Justicia Restaurativa: Una Dinámica Social. Librería jurídica Sánchez. Medellín.

Britto, D. (2010). Justicia Restaurativa. Reflexiones sobre la experiencia de Colombia. Universidad Técnica Particular de Loja. Colección Cultura de la Paz. Ecuador.

Eliaerts, C. (2002). Constructief sanctioneren van jeugddelinquenten: een kommentaar bij vijf jaar werkingvan). - Brussel: VUBPress, 2002. - 293 S. - ISBN: 90-5487-316-7 - Criminologische studies. En línea: http://www.vub.ac.be/SCRI/downloads/Eliaerts/Boeken/ConstructiefSanctioneren.pdf

Mantilla, J. (2014). El acuerdo del Viernes Santo o la paz como nuevo diseño institucional compartido: lecciones del proceso de paz en Irlanda del Norte en: Documentos de políticas públicas, 5, Julio. pp. 1-13.

Naciones Unidas. (2006). Manual sobre programas de justicia restaurativa. Serie de manuales sobre justicia penal naciones unidas. oficina de las naciones unidas contra la droga y el delito. Nueva York.

Pérez, J., y Zaragoza, J. Justicia restaurativa: del castigo a la reparación. En línea: https://archivos.juridicas .unam.mx/www/bjv/libros/7/3104/38.pdf

Rodríguez, G. (2011). Los límites del perdón. Notas sobre la justicia transicional en Sudáfrica, Centroamérica y Colombia en Justicia Juris, 7, II. pp. 55-66.

Teitel, R. (2003). Transitional Justice Genealogy en Harvard Human Rigths Journal, 16. pp. 69-94. 
Uprimny, R. (2006). Justicia transicional en perspectiva comparada: procesos transicionales, formas de justicia transicional y el caso colombiano. En: ¿Justicia transicional sin transición? Verdad, justicia y reparación para Colombia. Bogotá: DeJusticia.

Uprimny, R. y L.M. Lasso. (2004). "Verdad, reparación y justicia para Colombia: Algunas reflexiones y recomendaciones”, en VV.AA. Conflicto y seguridad democrática en Colombia. Temas críticos y propuestas, Bogotá, Fundación social, FESCOL, Embajada de Alemania, pp. 101-88.

Uprimny, R., \& Saffon, M. (2005). Justicia transicional y justicia restaurativa: tensiones y complementariedades. En entre el perdón y el paredón: preguntas y dilemas de la justicia transicional. Compilado por Angelika Rettberg. Universidad de los Andes. Facultad de Ciencias Sociales. Departamento de Ciencias Políticas. CESO. Ediciones Uniandes; Canadá: International Development Research Centre.

Wright, M. (1991): Justice for Victims and Offenders, Philadelphia, Open University Press. 